\title{
5q- Syndrome in Transformation to the Philadelphia Chromosome Positive Acute Myeloblastic Leukemia
}

Ana Vidović ${ }^{1,2^{*}}$, Gradimir Janković ${ }^{1,2}$, Nada Suvajdžić Vukovićc ${ }^{1,2}$, Ziv Radisavljevic3, Jelica Jovanović ${ }^{1}$, Marija Denčić Fekete ${ }^{1}$, Biljana Todorić-Živanović ${ }^{4}$ Irena Đunić ${ }^{1}$, Marijana Virijević ${ }^{1}$, Jelena Bila ${ }^{1,2}$, Nataša Čolovićc ${ }^{1,2}$ and Dragica Tomin ${ }^{1,2}$

1Clinic of Hematology, Clinical Centre of Serbia, Belgrade, Serbia

2Medical Faculty, University of Belgrade, Serbia

3Brigham and Women's Hospital, Harvard Medical School, Boston, USA

4Military Medical Academy, Belgrade, Serbia

${ }^{*}$ Corresponding author: Ana Vidovic, MD., PhD, Clinic for Hematology, Clinical Center of Serbia, Koste Todorovic 2, 11000 Belgrade, Serbia, Tel: +381638151427; Fax: +381113065112; E-mail: vidana103@gmail.com

Rec date: Jan 09, 2014, Acc date: Feb 18, 2014, Pub date: Feb 25, 2014

Copyright: (C) 2014 Vidovic A, et al. This is an open-access article distributed under the terms of the Creative Commons Attribution License, which permits unrestricted use, distribution, and reproduction in any medium, provided the original author and source are credited.

\begin{abstract}
Background: A rare 5q- syndrome subtype (OMIM:153550) of the myelodysplastic syndrome (MDS) evolved to the Philadelphia $(\mathrm{Ph})$ chromosome positive acute myeloblastic leukemia (AML) is presented. The MDS is an acquired clonal stem cell disorder frequently associated with a variety of chromosomal abnormalities. The most common karyotype abnormalities in MDS are del(5q), -7 and +8 . The $t(9 ; 22)(q 34 ; q 11)$ results in the formation of the $\mathrm{Ph}$ chromosome and generates an active chimerical BCR-ABL tyrosine kinase most commonly associated with chronic myelogenous leukemia (CML) and adult precursor B-acute lymphoblastic leukemia (B-ALL). The Ph chromosome positive MDS and AML are uncommon with only $1-2 \%$ of newly diagnosed cases.
\end{abstract}

Case report: We present a 72-year old woman with MDS. The HG-banding technique applied on unstimulated bone marrow cells showed 46,XX, del(5)(q13q33)[10]/46,XX. Ten months later, the white blood cell (WBC) count increased to $72 \times 109 / /$, with $60 \%$ of myeloblasts in the formula. The bone marrow aspirate was hypercellular with $50 \%$ blasts. The cytogenetic study demonstrated the presence of $\mathrm{Ph}$ chromosome together with the initial del $(5 \mathrm{q})$ in the same cellular clone. Chemotherapy with hydroxyurea and low-dose cytosine arabinoside was followed by an increase in WBC count to $98 \times 109 / \mathrm{l}$. The dosage of cytosine arabinoside was escalated to $100 \mathrm{mg} / \mathrm{m}^{2}$, for 7 days resulting in a drop in the WBC count to $12 \times 109 / /$. The follow-up bone marrow aspirations showed a further progression of disease with $>70 \%$ of myeloblasts in the myelogram. The patient lived 10 months after the initial diagnosis of MDS was made and another 4 months after the diagnosis of secondary AML.

Conclusion: The karyotype evolution from the solely $5 q$ - to the $5 q$ - and Ph-positive clone in the MDS in transformation to secondary AML (sAML) is a rare event. To our knowledge, this is a second such case reported in the literature. Based on current literature, we discuss possible links between the $5 q$ - syndrome, BCR/ABL-negative chronic myeloproliferative neoplasms and the BCR/ABL-positive leukemias.

Keywords 5q- syndrome; $\mathrm{Ph}$ chromosome; MDS; AML transformation

\section{Introduction}

The "5q- syndrome" as an independent subtype of the myelodysplastic syndrome (MDS, OMIM:153550) accounting for a third of a bulk of hematologic patients carrying 5q-deletions. Characteristically, small megakaryocytes with round, unlobulated nuclei and abnormal erythropoiesis are present in the bone marrow (BM) aspirate. Karyotype evolution and progression to AML is uncommon. Most patients with affected 5q31 lose the following candidates genes: EGR1 (early growth response 1 protein), CSF1R (CSF1 receptor gene) and IRF1 (interferon regulatory factor 1) [1]. The Philadelphia $(\mathrm{Ph})$ chromosome is generated by the reciprocal translocation $\mathrm{t}(9 ; 22)(\mathrm{q} 34 ; \mathrm{q} 11.2)$ where the $\mathrm{c}-\mathrm{ABL}$ gene from chromosome 9 fuses with the BCR gene on chromosome 22. This translocation results in expression of the p210 BCR-ABL oncoprotein in patients with chronic myeloid leukemia (CML) and the p190 BCR-
$\mathrm{ABL}$ oncoprotein in the majority of Ph-positive patients with ALL $[2,3]$.

\section{Materials and Methods}

The studies included cytology, cytogenetics, immunophenotyping with multiparameter flow immunocytometry and the molecular genetics analyses [3]. Unstimulated bone marrow (BM) cells were cultured for 24 hours and the chromosomes were trypsin G-banded following standard procedures [4]. Screening for the BCR-ABL transcripts was done using RT-PCR $[5,6]$.

\section{Case report}

A 71-year-old female was referred the Clinic of Hematology, in November 2007 for evaluation of the macrocytic anemia of one year duration that failed to respond to folate. Her physical examination was unremarkable except for pallor. The full blood count included hemoglobin of $81 \mathrm{~g} / \mathrm{l}, \mathrm{MCV} 96 \mathrm{fl}$, platelets 223x109/l, and the WBC 
Citation: Vidovic A, Jankovic G, Vukovic S N, Radisavljevic Z, Jovanovic J, et al (2014) $5 q$ - Syndrome in Transformation to the Philadelphia Chromosome Positive Acute Myeloblastic Leukemia. Carcinog Mutagen 5: 164. doi:10.4172/2157-2518.1000164

Page 2 of 3

count 5,5x109/1 (52\% neutrophils, 42\% lymphocytes, $6 \%$ monocytes). The BM aspirate was normocellular with $15-18 \%$ of $\mathrm{CD} 34+$ and CD117+ mononuclear cells. The megakaryocytes were unlobulated with rounded nuclei, typical for the 5q- syndrome subtype of MDS.

The cytogenetic study on the BM showed 46,XX, del(5)(q13q33) [10]/46,XX[10] (Figure 1). The diagnosis of the 5q- syndrome subtype of MDS was made. The patient was treated with the red blood cell transfusions only. In September 2008, she was hospitalized because of extreme malaise. The liver was $+3 \mathrm{~cm}$ and the spleen $+1 \mathrm{~cm}$ below respective costal margins. The hemoglobin was $53 \mathrm{~g} / \mathrm{l}$, platelets $60 \times 109 / 1$, and the WBC count $72,6 \times 109 / 1$ with $60 \%$ myeloblasts. The LDH activity in the serum was $1489 \mathrm{U} / \mathrm{l}$. There were $50 \%$ of blasts (25\% POX positive) in the hypercellular BM. Flow immunocytometry showed that $45 \%$ of mononuclear BM cells were positive for CD45low with the phenotype (HLA-DR, CD34, CD117, CD13, CD33, MPO, $\mathrm{CD} 11 \mathrm{~b})+$. The clone evolution was evidenced by the presence of $\mathrm{Ph}$ chromosome (b3a2 form) in the metaphases which also retained the initial del(5q) (Figure 2). The AML secondary (sAML) to her 5qsyndrome has been treated with cytosine arabinoside $(100 \mathrm{mg} / \mathrm{m} 2$ days 1-7). The WBC count decreased to $12 \times 109 / 1$ but with $70 \%$ blasts in the formula. She developed the purpura and painful infiltrates in the right maxilla and the left hand wrist. Despite intensive care she died of progressive sAML in December 2008. The 5q- syndrome lasted 10 months and the Ph-positive sAML lasted next 4 months, with overall survival of 14 months.

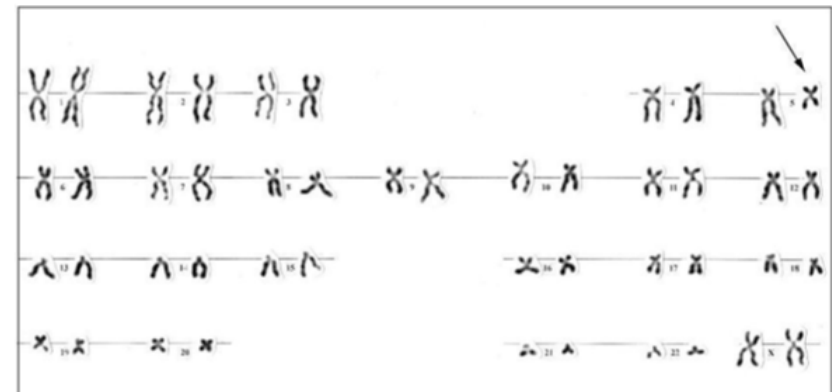

Figure 1: Karyogram 46,XX,del(5)(q13q33)

\section{Discussion}

This lady patient initially presented with the $5 \mathrm{q}$ - syndrome. The $5 \mathrm{q}-$ deletion (q13q33) has been associated with haplo insufficiency of the ACSL6 (OMIM: 604443) and IRF1 (OMIM: 147575) genes at 5q31.1, CSF1R (OMIM: 164770) and PDGFRB (OMIM: 17341) genes at 5q32, and the RPS14 (OMIM: 130620) gene at 5q33.1.6 In single patients with refractory anemia with excess of blasts with basophilia, AML with eosinophilia, and acute eosinophilic leukemia, ACSL6 was identified as a fusion partner to ETV6 (OMIM: 600618) in recurrent $t(5 ; 12)$ (q31;p13) translocations [7]. The IRF1 is located at least $200 \mathrm{~kb}$, but not more than $1,600 \mathrm{~kb}$, telomeric to the IL3 (OMIM: 147740) and GMCSF (CSF2; OMIM: 138960) genes at this region [8]. Among genes in the $5 \mathrm{q} 31.1$ region, only IRF1 was consistently deleted at one or both alleles in thirteen patients with leukemia or MDS associated with changes at $5 \mathrm{q} 31$. Le Beau et al. found that the FMS and GM-CSF genes were both deleted from the chromosome $5 \mathrm{q}$ - in BM cells in two patients with refractory anemia and $\operatorname{del}(5)(\mathrm{q} 15-\mathrm{q} 33.3)$ [8].
Reciprocal chromosomal translocation that involves 5q31-q33 was observed in a minority of patients with BCR-ABL-negative myeloproliferative neoplasms. The most common of these fuses the ETV6 gene to the PDGFRB gene but four additional partner genes are known: H4 (D10S170), HIP1, CEV14 (TRIP11), and rabaptin-5. Clinically, most patients present with a myeloproliferative disorder with eosinophilia, eosinophilic leukemia, or chronic myelomonocytic leukemia and thus fall into the broad category of myeloproliferative neoplasms/myelodysplastic syndromes (MPN/MDS). Patients with rearrangement of the PDGFRB might be classified in the future as a distinct subgroup of MPN/MDS [9]. A small proportion of patients with chronic myeloproliferative neoplasmss have constitutive activation of the PDGFRB gene, resulting in many cases from a chromosome translocation such as $t(5 ; 12)$, which creates a fusion gene with ETV6 (OMIM: 600618). Fusions between PDGFRB and H4/ D10S170 (OMIM: 601985), rabaptin-5 (RABPT5; OMIM: 603616), and huntingtin-interacting protein-1 (HIP1; OMIM: 601767) have also been reported in cases of chronic myeloproliferative neoplasms. The protein tyrosine kinase activity of PDGFRB, like that of ABL1 (OMIM: 189980) and KIT (OMIM: 164920), is inhibited by Gleevec (imatinib mesylate). This compound has been shown to be effective in the treatment of CML (OMIM: 151410) and gastrointestinal stromal tumors (OMIM: 606764), which are caused by abnormalities in the ABL1 and KIT genes, respectively. Apperley et al. demonstrated that Gleevec was effective in the treatment of chronic myeloproliferative neoplasms with rearrangements of the PDGFRB gene [10]. These molecular details suggest the existence of a rather remote and subtle link between the $5 \mathrm{q}$ - syndrome and the BCR/ABL-positive CML, and presumably also between 5q- syndrome and the BCR/ABL-positive AML. However, translocations involving chromosome bands $5 \mathrm{q} 31$ or $5 \mathrm{q} 33$, resulting in fusion of the PDGFRB gene with other genes, usually associate with BCR-ABL-negative chronic myeloproliferative disorders [11] The presented patient is a second to be reported following the first similar case reported by Bacher et al. [1].

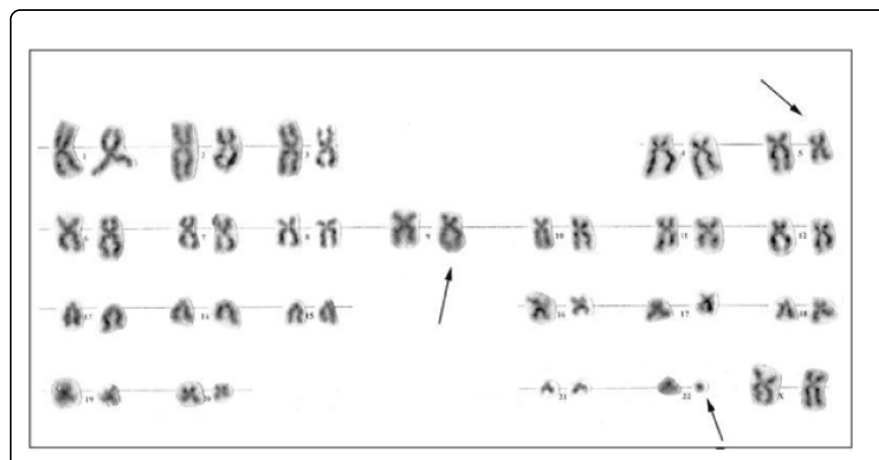

Figure 2: Karyogram 46,XX,del(5)(q13q33),t(9;22)(q34;q11)

The $5 \mathrm{q}$ - syndrome is characterized by a defect in differentiation of the erythron due to a recurring somatic deletion of a $1.5-\mathrm{Mb}$ region (containing 40 genes) on chromosome 5q. Using an RNA-mediated interference-based approach, partial loss of function of the ribosomal subunit protein RPS14 phenocopied the disease in normal hematopoietic progenitor cells [1]. Forced expression of RPS14 rescued the disease phenotype in patient-derived BM cells. In addition a block was identified in the processing of preribosomal RNA in RPS14-deficient cells that is functionally equivalent to the defect in Diamond - Blackfan anemia (OMIM: 105650), thus linking the molecular pathophysiology of the $5 \mathrm{q}$ - syndrome (the somatic deletion 
Citation: Vidovic A, Jankovic G, Vukovic S N, Radisavljevic Z, Jovanovic J, et al (2014) $5 q$ - Syndrome in Transformation to the Philadelphia Chromosome Positive Acute Myeloblastic Leukemia. Carcinog Mutagen 5: 164. doi:10.4172/2157-2518.1000164

Page 3 of 3

of one allele of RPS14) to a congenital syndrome causing BM failure [12]. Changes in the RPS14 gene and a partial loss of function of the ribosomal subunit protein RPS14 were speculated to possibly cooperate in rare patients with the $\mathrm{t}(9 ; 22)[9,12]$.

Our patient demonstrated the association of $5 \mathrm{q}$-deletion and the $\mathrm{Ph}$ chromosome within single cells of the same clone which evolved from initial 5q- syndrome to AML [1]. In AML, mutations suppressing differentiation ("class-II-mutations") cooperate with "class-Imutations" which increase cell proliferation [1]. In rare cases of myeloid malignancy, the class-I fusion mutation BCR-ABL1 has been reported to cooperate with class-II-mutations in the blastic phase of CML. Bacher et al. have reported a patient with sAML following initial MDS with a solitary 5q-deletion. Their patient had the $\mathrm{Ph}$ chromosome (bcr-abl of b3a2) in his karyotype similar to the present patient [1].

Late appearance of a secondary $\mathrm{Ph}$ chromosome has been documented in rare cases of MDS, B- and T-ALL, CML, acute biphenotypic leukemia and AML [13,14]. Appearance of the $\mathrm{Ph}$ chromosome at relapse or during the terminal stage of a disease indicates that the $\mathrm{Ph}$ rearrangement plays a role not only in the initiation leukemogenesis, as in CML, but also in the clonal evolution related to progression of neoplasms other than CML. More data are required to understand how different gene rearrangements are temporally organized over the natural course of disease to understand the biologic and molecular features of leukemias as presumably hierarchical/branched processes.

\section{Acknowlegments}

This study was supported in part by the Ministry of Science and Technological Development of the Republic of Serbia, Grant No. 41004.

\section{References}

1. Bacher U1, Haferlach T, Alpermann T, Zenger M, Hochhaus A, et al. (2011) Subclones with the $t(9 ; 22) / B C R-A B L 1$ rearrangement occur in AML and seem to cooperate with distinct genetic alterations. $\mathrm{Br} \mathrm{J}$ Haematol 152: 713-720.

2. Kern W, Dannhauser-Riedl S, Ratei R, Schnittger S, Schoch C, et al. (2003). Detection of minimal residual disease in unselected patients with acute myeloid leukemia using multiparameter flow cytometry for definition of leukemia-associated immunophenotypes and determination of their frequencies in normal bone marrow. Haematologica 88: 646-53.

3. Berger R1, Chen SJ, Chen Z (1990) Philadelphia-positive acute leukemia. Cytogenetic and molecular aspects. Cancer Genet Cytogenet 44: 143-152.

4. Novak A1, Kruskic M, Ludoski M, Jurukovski V (1994) Rapid method for obtaining high-quality chromosome banding in the study of hematopoietic neoplasia. Cancer Genet Cytogenet 74: 109-114.

5. Moravcová J1, Lukásová M, Starý J, Haskovec C (1998) Simple competitive two-step RT-PCR assay to monitor minimal residual disease in CML patients after bone marrow transplantation. Leukemia 12: 1303-1312.

6. NCBI Map Viewer. Human Genome Overview (Built 37.3) BLAST Human Sequence/ Chromosome 5 (q12q35).

7. Yagasaki F1, Jinnai I, Yoshida S, Yokoyama Y, Matsuda A, et al. (1999) Fusion of TEL/ETV6 to a novel ACS2 in myelodysplastic syndrome and acute myelogenous leukemia with $\mathrm{t}(5 ; 12)(\mathrm{q} 31 ; \mathrm{p} 13)$. Genes Chromosomes Cancer 26: 192-202.

8. Le Beau MM, Westbrook CA, Diaz MO, Larson RA, Rowley JD, et al. (1986) Evidence for the involvement of GM-CSF and FMS in the deletion (5q) in myeloid disorders. Science 231: 984-987.

9. Steer EJ1, Cross NC (2002) Myeloproliferative disorders with translocations of chromosome 5q31-35: role of the platelet-derived growth factor receptor Beta. Acta Haematol 107: 113-122.

10. Apperley JF1, Gardembas M, Melo JV, Russell-Jones R, Bain BJ, et al. (2002) Response to imatinib mesylate in patients with chronic myeloproliferative diseases with rearrangements of the platelet-derived growth factor receptor beta. N Engl J Med 347: 481-487.

11. Baxter EJ, Kulkarni S, Vizmanos J-L, Jaju R, Martinelli G, et al, (2003). Novel translocations that disrupt the platelet-derived growth factor receptor beta (PDGFRB) gene in BCR-ABL-negative chronic myeloproliferative disorders. Br J Haematol 120: 251-256.

12. Ebert BL1, Pretz J, Bosco J, Chang CY, Tamayo P, et al. (2008) Identification of RPS14 as a 5q- syndrome gene by RNA interference screen. Nature 451: 335-339.

13. Chen L1, Stamatoullas A, Bastard C, Tilly H (2004) Secondary Philadelphia chromosome in a patient with acute lymphoblastic leukemia. Cancer Genet Cytogenet 152: 132-135.

14. Pederson-Bjergard J, Brondum-Nielsen K, Karle H, Johanson B (1997) Chemotherapy-related- and late appearing- Philadelphia chromosome in AML, ALL and CML. Similar events related to treatment with DNA topoisomerase II inhibitors? Leukemia 11: 1571-1574. 